\title{
Variação de curta escala temporal de bactérias, picofitoplâncton e nanoheterótrofos na região de Ubatuba - SP, Brasil
}

\author{
Hilda de Souza Lima MESQUITA \& Ana Júlia FERNANDES \\ Instituto Oceanográfico da Universidade de São Paulo \\ (Caixa Postal 66149, 05389-970, São Paulo, SP, Brasil)
}

- Abstract: An investigation on the temporal variation of the planktonic microbial community (bacteria, total picophytoplankton and nanoheterotrophs) was undertaken over 7 days period (from February 27 to March 4, 1988) in a coastal region of Ubatuba $\left(23^{\circ} \mathrm{S}, 45^{\circ} \mathrm{W}\right)$. Samples were obtained at the thermocline twice daily (at high and low tides) during daylight time. Average density of nanoheterotrophs (Nh) was $2.3 \times 10^{3}$ cells ml $\mathrm{m}^{1}$, ranging from 0.9 to $3.5 \times 10^{3}$ cells $\mathrm{ml}^{-1}$. Total picophytoplankton was represented mostly by chroococcoid cyanobacteria and varied from 1.0 to $7.6 \times 10^{4}$ cells $\mathrm{ml}^{-1}$. Bacterial numbers ranged from 1.0 to $2.7 \times 10^{6}$ cells $\mathrm{ml}^{-1}$. The oscillation pattern displayed by the bacterial populations was out of phase in relation to Chl-a variation. The time interval between Chl- $a$ peak and the bacterial one was approximately 24 hours. At the beginning of studied period, the interrelationship between nanoheterotrophs and bacteria-picophytoplankton was characterized by a coupled oscillation, suggesting a predator-prey interaction. During the last three days (Marsh 2-4) the densities of three populations have fluctuated in phase. The influences of weather conditions, tidal movements, and predation by microzooplankton and metazoans are discussed. Many factors can affect the relationships between nanoheterotrophs and bacterial-picophytoplankton, but the oscillation pattern observed in this report are not fortuitous and may indicate an intense predation activity of nanoheterotrophs on pico-organisms.

- Resumo: A variaçāo temporal da comunidade microbiana (bactérias, picofitoplâncton total e nanoheterótrofos) nas águas de Ubatuba $\left(23^{\circ} \mathrm{S} 45^{\circ} \mathrm{W}\right)$ foi estudada durante um período de 7 dias (de 27/02 a 04/03/1988). As amostras foram obtidas na termoclina, duas vezes ao dia (na estôfa da maré baixa e da maré alta) durante 0 período diurno. A densidade de nanoheterótrofos variou de 0,9 a $3,5 \times 10^{3}$ cels $\mathrm{ml}^{-1}$ apresentando valor médio de $2,3 \times 10^{3}$ cels ml$^{-1}$. Picofitoplâncton total foi representado principalmente por cianobactérias cocóides e sua densidade variou de 1,0 a $7,6 \times 10^{4}$ cels ml $^{-1}$. O número de bactérias variou de 1,0 a $2,7 \times 10^{6}$ cels ml ${ }^{-1}$. A população bacteriana apresentou um padrão de oscilação defasado em relação a variação das concentrações de $\mathrm{Cl} a$. O intervalo de tempo entre os valores máximos de $\mathrm{Cl} a$ e as densidades máximas de bactéria foi de aproximadamente 24 horas. No início do período de estudo, a interrelação entre nanoheterótrofos e bactérias-picofitoplâncton foi caracterizada por uma oscilação inversa, sugerindo uma interação predador- presa. A partir do dia 02 de março as 3 populaçōes variaram quase que em fase. As influências das condiçōes meteorológicas, do movimento das marés e da predação por microzooplâncton e metazoários sã̃o discutidas. A despeito dos vários fatores que podem afetar as interrelações entre nanoheterótrofos e bactérias- picofitoplâncton parece que o padrão observado não é errático e pode estar expressando uma intensa atividade predatória.

- Descriptors: Bacteria, Cyanobacteria, Nanoheterotrophs, Clorofila a, Predation, Temporal Variation, Abiotic Factors, Ubatuba: São Paulo, Brazil.

- Descritores: Bactérias, Cianobactérias, Nanoheterótrofos, Clorofila a, Predação, Variação Temporal, Fatores Abióticos, Ubatuba: São Paulo, Brasil. 


\section{Introdução}

Grande parte da dinâmica da matéria orgânica dissolvida no ambiente marinho se concentra nas populações de menor tamanho, onde estão o pico e o nanoplâncton (Pomeroy, 1974). O picoplâncton inclui todos os organismos autótrofos (cianobactérias, proclorofitas e algas eucarióticas) e heterótrofos (bactérias) na classe de tamanho entre 0,2 e $2,0 \mu \mathrm{m}$. Os organismos autótrofos e heterótrofos na classe de tamanho entre 2,0 e 20,0 $\mu \mathrm{m}$ constituem o nanoplâncton (Sieburth $e t$ al., 1978). As relaçōes tróficas entre os menores elementos de uma cadeia alimentar se constituem no que Azam et al. (1983) denominaram alça microbiana.

Fenchel (1982) descreveu as interrelaçōes existentes entre bactérias e nanoheterótrofos como uma oscilação inversa, com defasagem de 4 a 5 dias. Este padrão de interação foi também descrito por outros pesquisadores, porém, com intervalos de tempo diferentes entre o máximo da densidade de bactérias e o máximo da densidade de nanoheterótrofos (Sorokin, 1977; Burney et al., 1981; Davis et al., 1985; Andersen \& Sorensen, 1986) e, tem sido explicado como sendo uma interação predador-presa entre as duas populaçōes.

Protozoários fagotróficos, pertencentes ao nanoplâncton, são também considerados consumidores importantes do picofitoplâncton (Landry et al., 1984; Campbell \& Carpenter, 1986; Iturriaga \& Mitchell, 1986; Rassoulzadegan \& Sheldon, 1986; Caron et al., 1991).

Devido às dificuldades em analisar a interação microbiana do tipo predador-presa em sistemas naturais, a maior parte do conhecimento obtido nesta área foi baseada em experimentos de laboratório. Entretanto, a extrapolaçāo dos resultados de laboratório para as condiçōes de campo é dificultada pela complexibilidade das populações microbianas e pela existência de vários fạtores ambientais que afetam estas populaçōes no ambiente natural. Além disso; devido à predação de nanoheterótrofos por ciliados e pelo mesozooplâncton, a estrutura trófica microbiana torna-se ainda mais complexa.

Este trabalho tem o objetivo de descrever a variação "in situ", simultânea, de 3 grupos funcionais: picofitoplâncton, bactérias e, seu mais importante consumidor, o nanoplâncton heterotrófico, além de analisar as interaçōes entre estas populações em uma escala temporal de 7 dias.

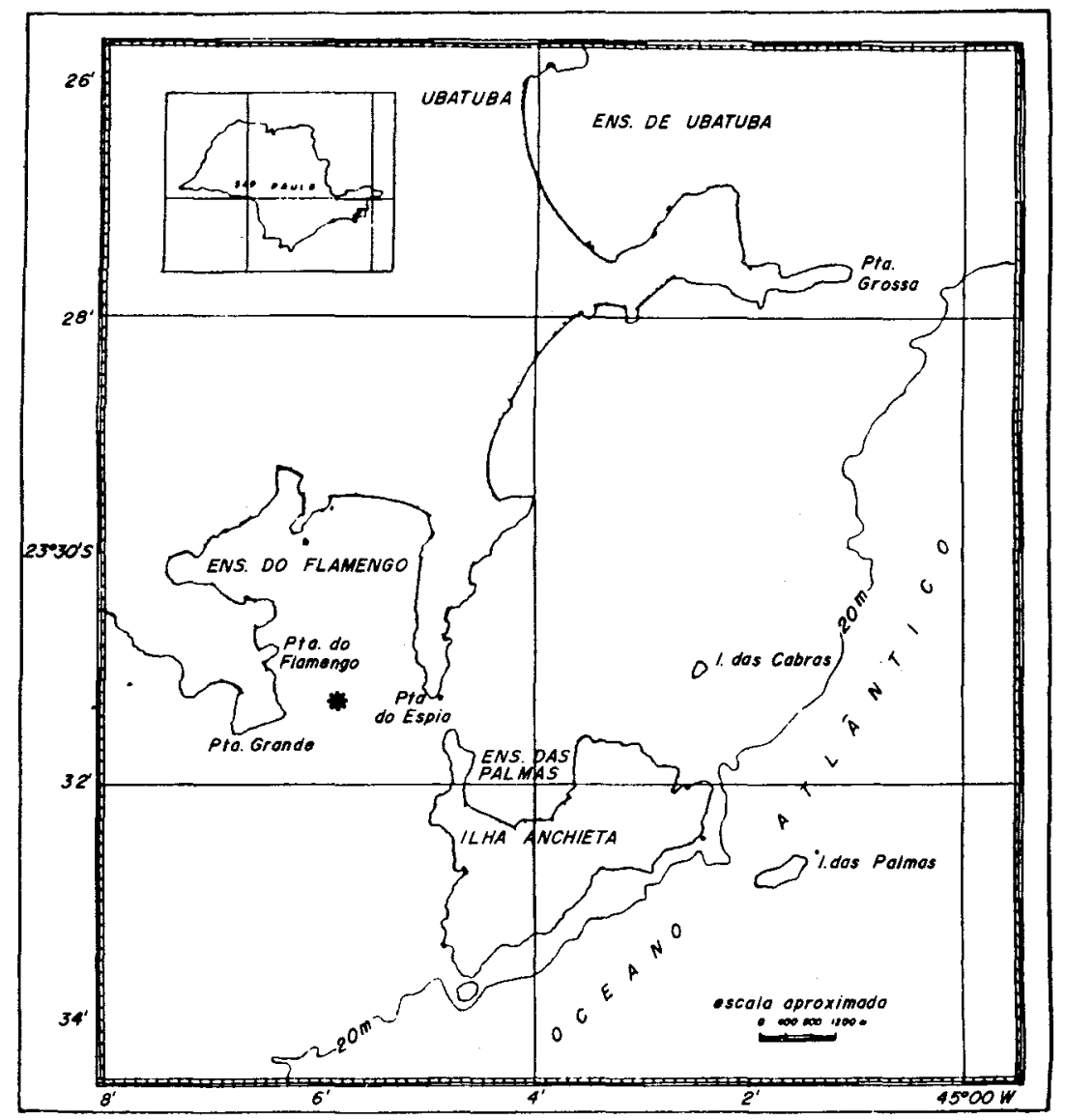

Fig. 1. Região de Ubatuba e localização da estação fixa. 
A regiāo costeira de Ubatuba é localizada no sudeste da costa brasileira a $23^{\circ} \mathrm{S} 25^{\circ} \mathrm{W}$ (Fig. 1). O sistema é considerado meso-oligotrófico e é caracterizado por temperaturas entre 14 e $24^{\circ} \mathrm{C}$ e salinidades entre 35 a $36,8 \%$. A produção primária é baixa, apresentando valores diários entre $400 \mathrm{e} 600 \mathrm{mg} \mathrm{C} \mathrm{m}^{-2}$ (Gianesclla-Galvão \& Saldanha-Corrêa*, 1995) e o nitrogênio tem sido considerado como fator limitante desta produção (Aidar et al., 1993).

As marés sāo semidiurnas com amplitudes máximas durante as marés de sizígia de 1,98 m (Mesquita \& Harari, 1984). Entretanto, as correntes de marés parecem ser fracas (Mesquita et al., 1979) nesta área.

\section{Material e métodos}

As amostras foram coletadas em estação fixa (profundidade local $40 \mathrm{~m}$ ), na região costeira de Ubatuba (Fig. 1), em profundidades correspondentes à $25 \%$ de penetração de luz, as quais foram determinadas de acordo com as leituras do disco de Secchi. A definição das profundidades de coleta de acordo com a penetração da luz foi feita em atendimento às necessidades do estudo da Produção Primária realizado, paralelamente à este trabalho, pelo grupo de Plâncton do Instituto Oceanográfico da Universidade de São Paulo. As profundidades de coleta variaram entre 5,5 e $10,0 \mathrm{~m}$ e se localizaram na termoclina.

As amostras foram obtidas duas vezes ao dia, na estôfa da maré baixa (aproximadamente às 07:00 h) e da maré alta (à tarde), durante 7 dias consecutivos, de 27/02 a 04/03/1988. Não foram obtidas amostras no período noturno.

As amostras foram preservadas com formaldcído à $5 \%$ de concentração final (Fernandes, 1994) e mantidas em geladeira, à temperatura aproximada de $6^{\circ} \mathrm{C}$ até seu processamento. Da coleta das amostras à contagem ao microscópio, decorreram aproximadamente 3 meses. Em laboratório, alíquotas de $15 \mathrm{ml}$, coradas com solução $0,01 \%$ de Alaranjado de Acridina, foram filtradas em membrana Nuclepore de $8,0 \mu \mathrm{m}$ de porosidade e o filtrado coletado em membrana Nuclepore de $3,0 \mu \mathrm{m}$ de porosidade com a finalidade de enumerar a população nanoplanctônica heterotrófica $(\mathrm{Nh})$ na classe de tamanho entre 3,0 e $8,0 \mu \mathrm{m}$. O nanoplâncton heterótrofo de tamanho superior a $8 \mu \mathrm{m}$

(*) Gianesella-Galvāo, S. M. F. \& Saldanha-Corrêa, F. M. P. 1995. A conceptual model for primary production in the Ubatuba region. In: INTERNATIONAL SYMPOSIUM ON ENVIRONMENTAL BIOGEOCHEMISTRY, XII. Abstract. Rio de Janeiro, 1995. p. 125. e o microzooplâncton não foram considerados neste trabalho devido ao fato de não serem consumidores importantes do picoplâncton (Andersen \& Fenchel, 1985; Sherr et al., 1986; Caron et al., 1991).

Para enumeração de bactérias, $1 \mathrm{ml}$ da amostra original foi filtrado em membrana Nuclepore de $0,22 \mu \mathrm{m}$, previamente corado com uma solução de Alaranjado de Acridina 0,01\%, de acordo com Hobbic et al. (1977).

$O$ picofitoplâncton foi também enumerado em membrana Nuclepore de $0,22 \mu \mathrm{m}$, após filtração de alíquota de $15 \mathrm{ml}$ de amostra. O picofitoplâncton total (PfT $=$ células $<3,0 \mu \mathrm{m})$ refere-se à cianobactérias com ficoeritrina-ficourobilina (PUB) e picocélulas que fluorescem vermelho sob luz de excitação azul. Observações eventuaiş das amostras ao microscópio de epifuorescência equipado com filtro verde mostraram que as cianobactérias com ficoeritrina-ficoeritrobilina (PEB) foram pouco abundantes. Cianobactérias com predominância de ficocianina são consideradas quantitativamente importantes apenas em ambientes de água doce (Waterbury et al., 1986).

As membranas Nuclepore utilizadas para a enumeração das populações microbianas, foram previamente enegrecidas com solução ácida de Irgalan Black (Hobbie et al., 1977).

Todas as contagens foram realizadas sob luz azul, com microscópio de epifluorescência, marca Nikkon (Optiphot), equipado com lâmpada de halogênio $50 \mathrm{~W}$, filtro de excitação IF410-485, espelho dicróico DM505 e filtro de absorção 515W. Para bactérias e picofitoplâncton foram contados, em média, 100 campos e para a avaliação de nanoheterótrofos, 80 campos.

A clorofila a, obtida somente nas amostras da maré baixa, foi determinada nas amostras totais e nas classes de tamanho entre $0,22-1,0 \mu \mathrm{m}, 1,0-3,0 \mu \mathrm{m}$ e $3,0-8,0 \mu \mathrm{m}$, de acordo com Strickland \& Parsons (1972). No presente estudo, as frações menores foram englobadas em uma fração única: entre $0,22 \mathrm{e} 3,0 \mu \mathrm{m}$.

Os dados relativos à precipitação pluviométrica foram obtidos na Seção de meteorologia do Departamento de Occanografia Física do Instituto Oceanográfico.

A salinidade e o oxigênio dissolvido foram determinados de acordo com Grasshoff $e t$ al. (1983). A temperatura foi obtida através da correção das respectivas leituras nas garrafas de Nansen.

O sigma-t foi calculado de acordo com as tabelas da Unesco (Millero \& Poisson, 1981).

\section{Resultados}

A coluna de água esteve ligeiramente estratificada durante o período de estudo (como evidenciado na Figura 
2 para o dia 29 de fevereiro). Os valores de sigma-t, nas profundidades de amostragem, mostraram algumas diferenças ao longo dos dias e entre as marés baixas e altas (Fig. 3). As diferenças entre o sigma-t nas marés alta e baixa são devidas mais ao efeito da radiação solar na temperatura da água do que às diferenças de salinidade. As diferenças observadas não nos permitem assegurar que as coletas tenham sido realizadas em uma mesma massa de água.

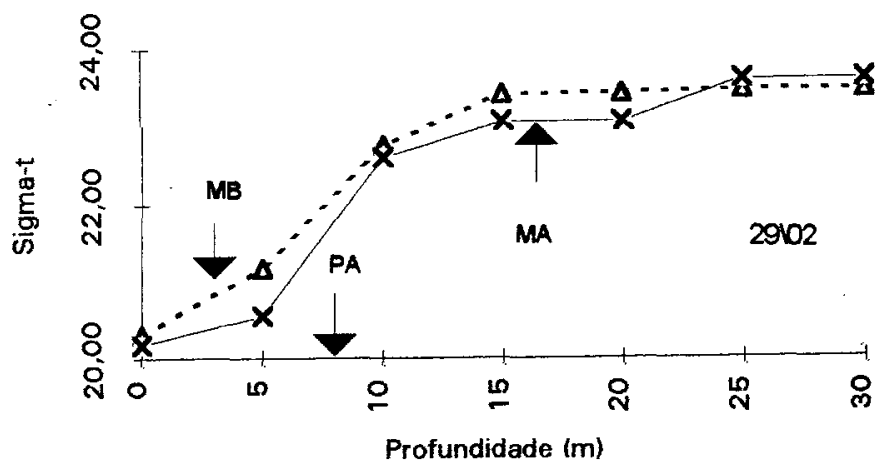

Fig. 2. Perfil do sigma-t, indicando estratificação da coluna de água, no dia 29 de fevereiro. $M B=$ maré baixa; $M A=$ maré alta; $P A=$ profundidade de amostragem.

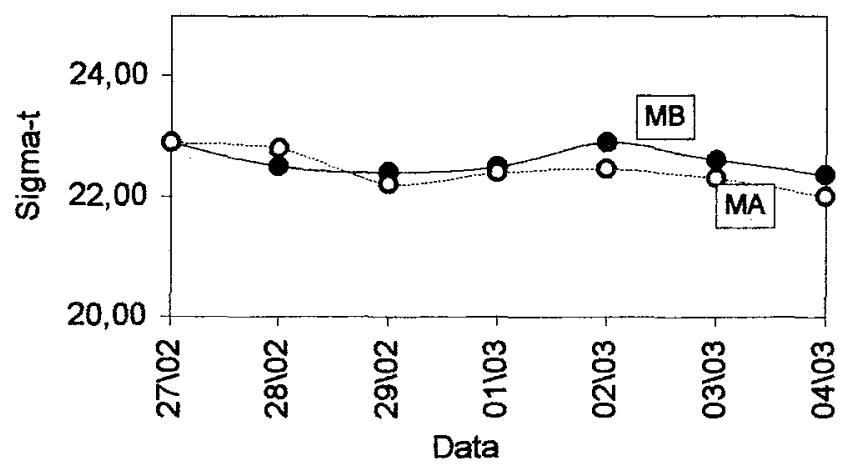

Fig. 3. Variação do sigma-t, nas profundidades de coleta, na maré alta (MA) e na maré baixa (MB).

O nível de água na maré alta foi mais variável do que na maré baixa (Fig. 7).

O fraco período de chuvas que teve início no dia $29 \mathrm{de}$ fevereiro, foi precedido por um decréscimo da penetração de luz na coluna de água (Fig. 4).

No início do período de estudo a água esteve supersaturada em oxigênio. Esta supersaturação coincidiu com o máximo da biomassa fitoplanctônica. A partir do dia 01 de março ocorreu subsaturação da água em oxigênio (Fig. 5).

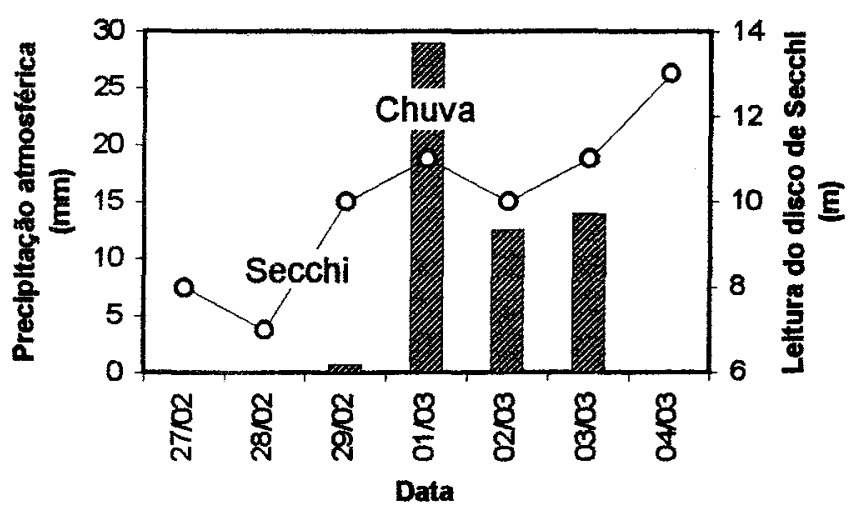

Fig. 4. Variação da precipitação atmostérica e das leituras do disco de Secchi durante o período de estudo.

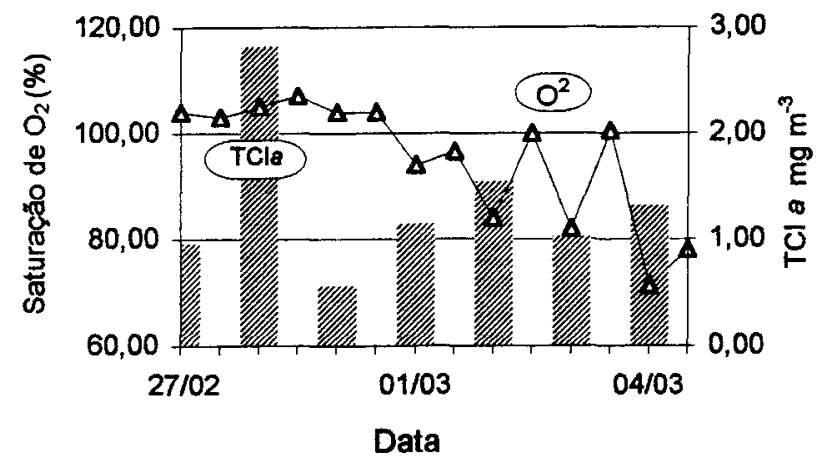

Fig. 5. Variação da concentração de clorofila a total ( $\mathrm{TCl}$ a) e dos valores de saturação de oxigênio dissolvido $\left(\mathrm{O}_{2}\right)$, no decorrer do período de estudo.

A análise da interrelação entre os 3 componentes da comunidade microbiana será feita considerando a variação, dia após dia, dos dados obtidos em marés baixas e altas.

A densidade do picofitoplâncton total (PfT $<3,0 \mu \mathrm{m}$ ) variou de 1,03 a $7,60 \times 10^{4} \mathrm{ml}^{-1} \mathrm{e}$, foi quase sempre, representado por cianobactérias cocóides contendo ficoeritrina-ficourobilina. $O$ padrão de variação desta população foi caracterizado por aumentos nos dias 27,02 e 04. Descréscimos na população ocorreram dias $28,29,01$ e 03 . A variação da concentração de clorofila a, na categoria de tamanho $<3,0 \mu \mathrm{m}$, não revelou a mesma magnitude de variação da população fitoplanctônica embora o padrão de variação fosse similar (Fig. 6). 


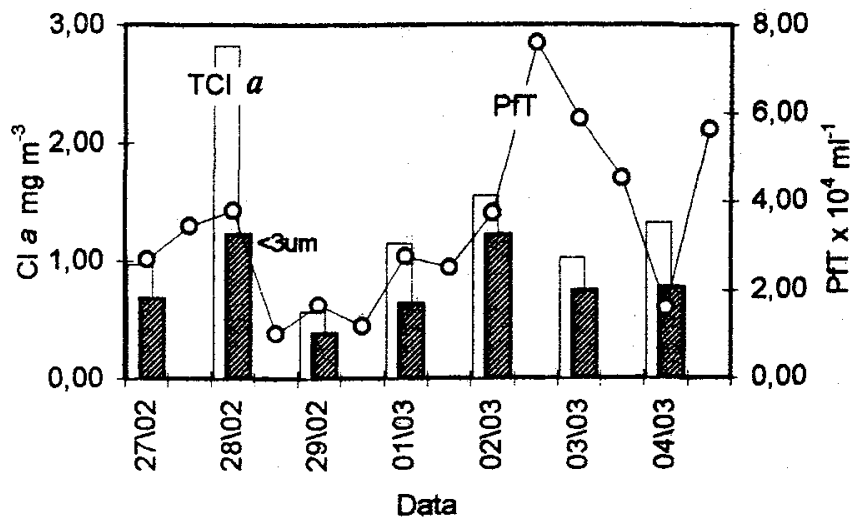

Fig. 6. Variação da densidade de picofitoplâncton total (PfT) e da concentração de clorofila a total (TCla) e fração $<3,0 \mu \mathrm{m}$ no decorrer do período de estudo.

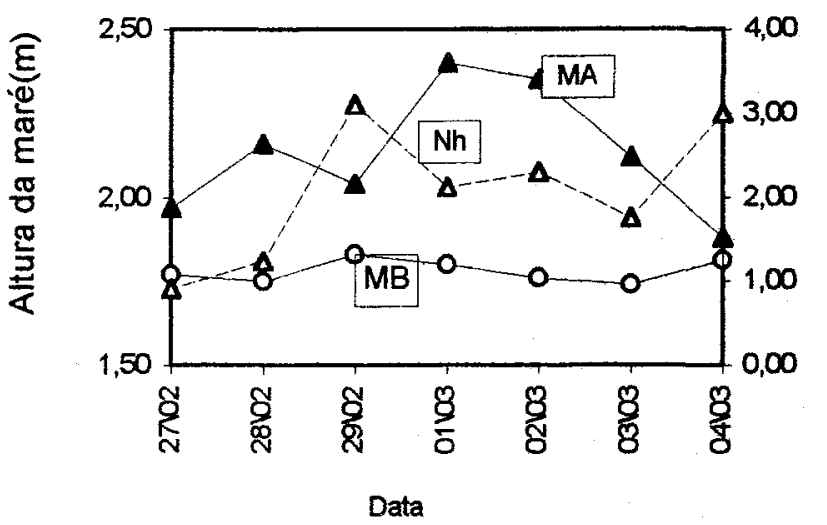

Fig. 7. Variação do nível da água na maré alta $(\mathrm{MA})$ e na maré baixa $(M B)$ e da população de nanoheterótrofos $(\mathrm{Nh})$, durante o período de estudo.

A densidade de nanoplâncton heterotrófico $(3,0$ $\mu \mathrm{m}-<3,0 \mu \mathrm{m})$ variou de 0,97 a $3,46 \times 10^{3} \mathrm{ml}^{-1}$. No início do período de estudo, a densidade de nanohetcrótrofos $(\mathrm{Nh})$ foi menor do que nos dias subseqüentes. $O$ padrāo de variação foi geralmente caracterizado pela alternância de valores altos e baixos. Relação inversa entre as densidades de nanoheterótrofos e a variação do nível da água na maré alta foi evidente (Fig. 7).

A abundância de bactérias (BT) variou de 1,00 a 2,69 x $10^{6} \mathrm{ml}^{-1}$. A amplitude de variação desta população, nos diversos dias do período de estudo, foi relativamente constante, excetơ no dia 29. A análise da oscilação das populaçōes bacteriana e nanoheterotrófica, ao longo do período de 7 dias (Fig. 8), mostra que, somente nos dias 27 e 29 as duas populações estiveram fora de fase. Nos demais dias, em geral, ambas as populações mostraram um padrão regular, caracterizado por flutuaçōes quase em paralelo.

Bactérias c clorofila a $(\mathrm{Cla})$ mostraram relaçāo inversa, com intervalo de tempo de 24 horas, entre seus valores máximos (Fig. 9).

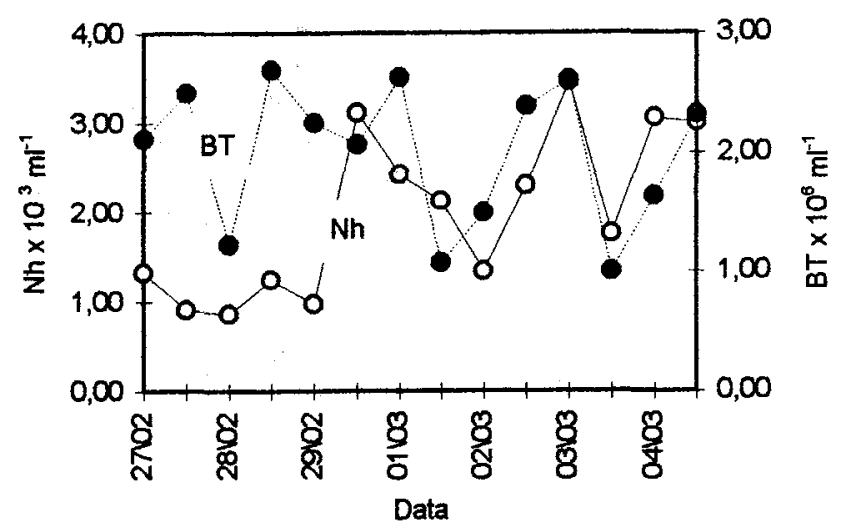

Fig. 8. Variação da densidade de bactérias (BT) e de nanoheterótrofos ( $\mathrm{Nh}$ ), no decorrer do período de estudo.

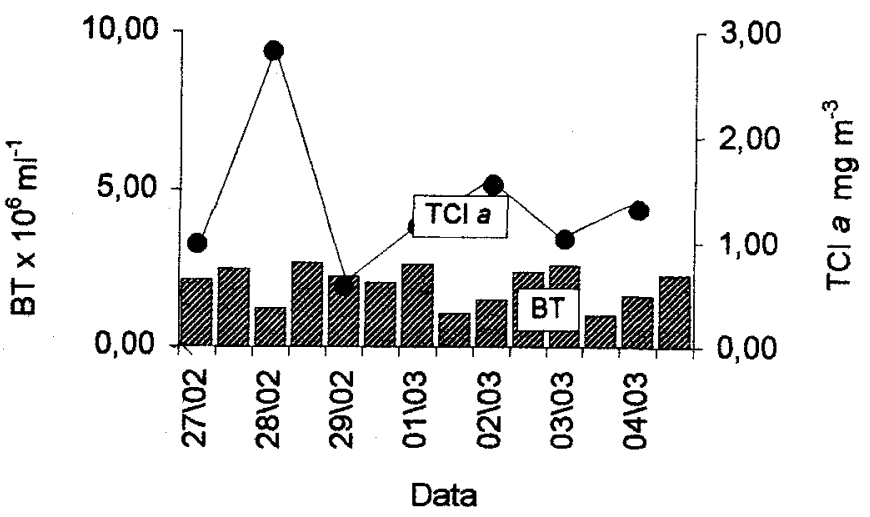

Fig. 9. Variação da densidade bacteriana (BT) e das concentrações de clorofila a total (TCla), durante o período de estudo.

As oscilações das populaçōes de Nh e de PfT estiveram defasadas nos 3 primeiros dias de amostragem. Nos dias subseqüentes, as oscilações ocorreram em fase (Fig. 10). A oscilação inversa entre a população nanoheterotrófica e picofitoplanctônica é mais evidente se for considerada a concentração de clorofila a na fração de tamanho $<3,0 \mu \mathrm{m}$, ao invés do número de células (Fig. 11). Neste caso, é 
possível observar que oscilação inversa ocorre ao longo do período de 7 dias com um intervalo de tempo de 24-48 horas, entre dois máximos consecutivos. Entretanto, a utilização dos dados de clorofila a implica em resolução de amostragem de 24 horas já que a clorofila a foi medida somente no período da manhã, em maré baixa.

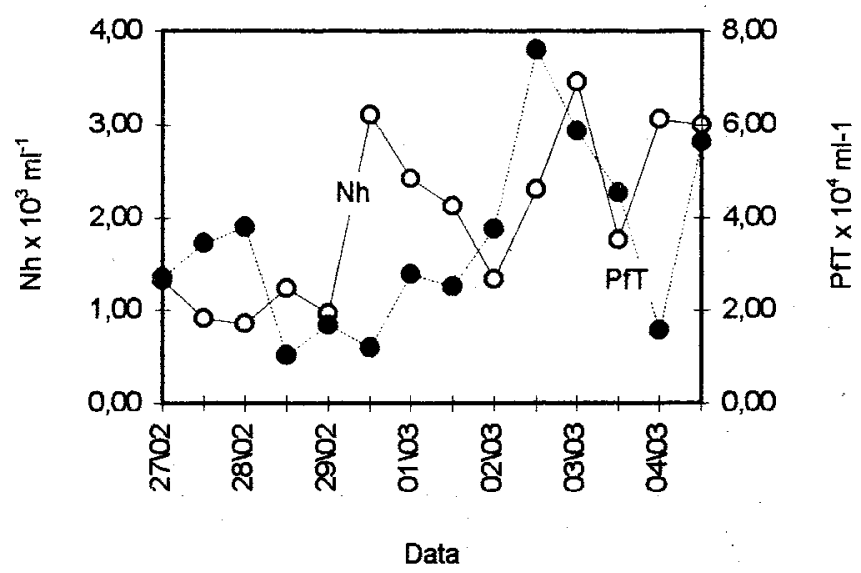

Fig. 10. Variação da densidade de nanoheterótrofos $(\mathrm{Nh})$ e de picofitoplâncton total (PfT), durante o período de estudo.

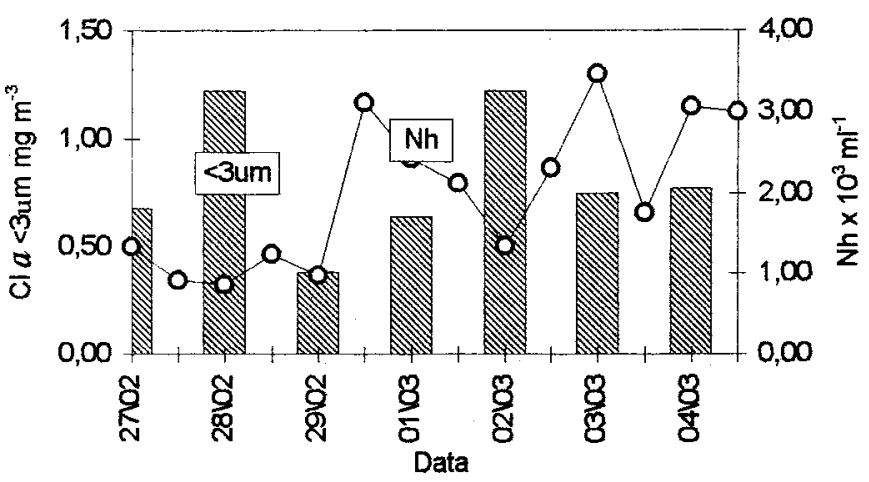

Fig. 11. Variação da densidade de nanoheterótrofos $(\mathrm{Nh})$ e da concentração de clorofila a na fração $<3,0 \mu \mathrm{m}(\mathrm{Cl}$ a $3,0 \mu \mathrm{m})$, no decorrer do período de estudo.

\section{Discussão}

A densidade de bactérias na região de Ubatuba é geralmente da ordem de $10^{6}$ células $\mathrm{ml}^{-1}$ (Mesquita, 1993).
Flutuações de populações microbianas, em escala de tempo pequena, foram registradas por alguns autores, para águas costciras e occânicas (Fuhrman et al., 1985; Coffin \& Sharp, 1987). O crescimento bacteriano em ambientes aquáticos depende de nutrientes $\mathrm{e}$, principalmente, do aumento de matéria orgânica lábil (Larsson \& Hagstrom, 1982), além da ausência ou redução da pressão de predação por nanoheterótrofos (Coffin \& Sharp, 1987). Em regiōes oceânicas oligotróficas, o crescimento bacteriano é limitado pelo baixo desenvolvimento das populações fitoplanctônicas. A importância das populações fitoplanctônicas como fonte de matéria orgânica para o desenvolvimento bacteriano é menor em águas costeiras, em decorrência da entrada de matéria orgânica alóctone através da drenagem continental, dos rios, da urbanização e da presença de macroalgas.

No presente trabalho, a relação inversa encontrada entre bactérias e biomassa fitoplanctônica mostra que o crescimento bacteriano ocorre depois dos máximos de clorofila a, a despeito das características costeiras desta área. Considerando-se que, na regiāo de Ubatuba o crescimento do fitoplâncton é limitado por nutrientes (Aidar et al., 1993) e apresenta alta variabilidade em curto intervalo de tempo, é possível presumir a existência de mecanismos intermitentes de limitação de nutrientes e, conseqüentemente, de produção orgânica. Além disso, as mudanças nas condições ambientais, iniciadas no dia $28 \mathrm{de}$ fevereiro, com um decréscimo da penetração de luz na coluna de água, parecem ter afetado as populaçōes autotróficas (baixo valor de $\mathrm{Cl}$ a no dia 29) causando uma mudança nas condições de oxigenação da água. A partir do dia 01 de março, a água torna-se subsaturada em oxigênio sugerindo piora das condições fisiológicas do fitoplâncton. Portanto, o desenvolvimento da população bacteriana parece estar ligado ao decaimento da população fitoplanctônica. Estes mecanismos teriam determinado a dinâmica da estrutura trófica microbiana da região costeira de Ubatuba, durante o período de estudo.

As densidades de picofitoplâncton não são tão altas como as registradas em algumas regiōes temperadas (Waterbury et al., 1986), mas são similares às encontradas na maioria dos mares. A despeito disto, nesta área, e na maior parte do ano, o picofitoplâncton compreende uma fração significativa da biomassa autotrófica, sendo produtor primário importante, (Teixeira \& Gaeta, 1991; Gianesella-Galvão, comun. pess.). Durante o período de estudo, na região de Ubatuba, como em outros locais (Joint et $a l, 1986)$, o picofitoplâncton que fluoresce vermelho,

Gianesella-Galvão, S. M. F. (1996). Instituto Oceanográfico USP, São Paulo. 
representou uma fração pequena da população picofitoplanctônica total. O picofitoplâncton foi representado principalmente por cianobactérias com ficoeritrina-ficourobilina.

O consumo de cianobactérias no ambiente natural têm sido registrado no meio marinho e em sistemas de água doce (Johnson et al., 1982; Landry et al., 1984; Campbell \& Carpenter, 1986; Rassoulzadegan \& Sheldon, 1986; Nagata, 1988). Em amostras da região de Ubatuba constatou-se a presença de picocianobactérias em vacúolos de flagelados, ciliados e formas amebóides.

O padrão de oscilação apresentado pelas populações microbianas, nesta série temporal, pode ser separado em duas partes: a primeira, do dia 27 de fevereiro ao dia 01 de março, quando as flutuações de bactérias-picofitoplâncton e nanoheterótrofos estão defasadas, à exceção do dia 28 de fevereiro para bactérias. A segunda, do dia 02 de março em diante, quando as 3 populações oscilam em fase.

O padrão de oscilação inversa como o apresentado por estas populações nos 4 primeiros dias da série temporal, tem sido interpretado como interação predador-presa e analisado através de modelos baseados na teoria predador-presa de Lotka-Volterra (Andersen \& Fenchel, 1985). De acordo com esta teoria, a densidade das presas atinge valores máximos quando a densidade de seus predadores atinge níveis mais baixos. Entretanto, durante o dia 28 de fevereiro, ocorre um aumento concomitante das densidades de bactérias e nanoheterótrofos. Uma explicação possível para esta ocorrência, seria que a pressão de predação dos nanoheterótrofos sobre as bactérias teria sido menor do que a taxa de crescimento destas. A pressão de predação sobre a população bacteriana teria diminuído devido ao fato dos nanoheterótrofos estarem utilizando o picofitoplâncton como alimento. Esta utilização das cianobactérias é difícil de explicar com base nos resultados obtidos em estudos experimentais realizados por Caron et al. (1991). A baixa densidade de nanoheterótrofos registrada talvez indique a ocorrência de uma população diversa de predador. Além disto, a baixa densidade bacteriana neste momento poderia ter induzido a população nanoheterotrófica a se alimentar de picofitoplâncton, a despeito das baixas taxas de eficiência de crescimento de nanoheterótrofos quando estes se alimentam de cianobactérias (Caron et al.,op. cit.).

A partir do dia 02 de março, considerando a escala de tempo de amostragem do presente estudo, bactérias-picofitoplâncton e nanoheterótrofos oscilam em paralelo. A análise dos dados de sigma-t permite a inferir alguma homogeneidade nas condições hidrográficas a partir desta data (Fig. 3). Entretanto, a penetração de luz na coluna de água mudou e, conseqüentemente as profundidades de amostragem variaram. Portanto, nāo se pode assegurar que as mesmas populaçōes tenham sido amostradas a cada tempo.

As densidades de pico-organismos (bactérias e picofitoplâncton) em maré alta e em maré baixa, separadamente, durante os 7 dias de estudo, não mostraram diferenças que pudessem ser atribuídas à fase de maré. Além disto, a flutuação de pico-organismos, tanto na maré alta como na maré baixa, durante o período de 7 dias, nāo apresentou qualquer padrão que pudesse ser associado ao movimento de água causado pela maré. $O$ transporte de água feito pelas correntes de maré é de pouca significância nesta área (Mesquita et al., 1979). Entretanto, as densidades de nanoheterótrofos mostraram uma relação inversa com a variação do nível de água (na maré alta), sugerindo diluição da populaçāo ocasionada pelo aumento do volume de água. No entanto, a diluição da população parece não ter afetado o padrão geral de variação dos nanoheterótrofos. Pode-se especular que, se a população de nanoheterótrofos não tivesse sofrido o efcito da diluição, as densidades no decorrer do período seriam mais elevadas que aquelas realmente encontradas. Neste caso, seria observada uma relação inversa entre nanoheterótrofos e bactérias, ao invés da variação em paralelo detectada no dia 01 de março. A conseqüência de uma densidade mais elevada de nanoheterótrofos nos dias subseqüentes seria o de acentuar o padrão já exibido.

A alteração do padrão de oscilaçāo a partir do dia 01 de março, reflete a desestabilização da relação inversa entre nanoheterótrofos e suas presas devido, provavelmente, às mudanças nas condições meteorológicas. $O$ início do novo padrão de oscilação coincide com modificações nas condições ambientais e na oxigenação da água. Andersen \& Sorensen (1986), observaram que eventos hidrográficos como o fluxo de águas ricas em nutrientes, alteram o padrão das oscilações entre bactérias e nanoheterótrofos.

Por outro lado, a co-variação de diferentes populações, como evidenciado neste estudo, sugere também que o desenvolvimento destas populações poderia estar sendo controlado por um fator comum, tal como a predação por microzooplâncton ou por metazoários. Lessard \& Swift (1985), observaram que dinoflagelados heterotróficos e alguns ciliados de tamanho superior a $25 \mu \mathrm{m}$, podem se alimentar de bactérias e picofitoplâncton.

Entre os metazoários, salpas são generalistas e podem ingerir pico e nanoorganismos indistintamente. Entretanto, este tipo de organismo não foi observado nas amostras deste trabalho. Além disto, o crescimento intermitente de generalistas, em intervalo de tempo curto, não é citado na literatura pertinente e não foi observado na área estudada. A possibilidade de que as populações pico e nanoplanctônicas pudessem ter sido simultaneamente 
predadas é pequena, considerando-se que a variação de clorofila a não mostrou o mesmo padrão de variação que os pico-nanoorganismos.

A literatura a respeito da dinâmica da estrutura trófica microbiana afirma a importância do tamanho dos organismos nas relações predador-presa (Sheldon et al., 1972). Assim, bactérias e também os organismos picofitoplanctônicos, encontram- se na classe de tamanho que serve de alimento aos nanoheterótrofos. Bactérias também podem ser predadas por picoflagclados (Fuhrman \& McManus, 1984; Wright \& Coffin, 1984; Rassoulzadegan \& Sheldon, 1986; Ray et al., 1989; Whecler et al., 1989), os quais não foram levados em consideração neste trabalho. Por outro lado, de acordo com MacManus \& Fuhrman (1988), a bacterivoria por nanoheterótrofos estaria muito mais relacionada à produção bacteriana do que à abundância das mesmas. Neste caso, a prescnte série temporal nāo estaria expressando oscilações inversas entre as populações de bactérias e de nanoheterótrofos porque as análises foram realizadas com base na avaliação da densidade de bactérias e não de sua produção. Outrossim, a variação concomitante, em fase, de populações microbianas, pode ser um artefato causado pela resolução da amostragem. $O$ intervalo de amostragem utilizado no presente trabalho (5 e 19 horas) não teria sido adcquado para expressar diferenças temporais entre o desaparecimento de presas e o crescimento do predador. Neste caso, o lapso de tempo decorrido entre o máximo de bactérias-picoautótrofos e o de nanoheterótrofos seria menor do que os encontrados por outros autores (Sorokin, 1977; Burney et al., 1981, 1982; Davis et al., 1985; Andersen \& Sorensen, 1986). Os decréscimos do picofitoplâncton são relativamente menos expressivos que os de bactérias e podem ter ocorrido devido a menor pressão de predação dos nanoheterótrofos sobre os organismos picofitoplanctônicos e/ou, devido à efeitos compensatórios de condições mais favoráveis de luz e nutrientes. Portanto, concluí-se que o padrão de oscilação exibido pelas populações microbianas nesta série temporal, expressa mais suas interações do que o efeito dos fatorcs ambientais e/ou de artefatos de amostragem.

Considerando que a série de dados do presente estudo é pequena e não foi replicada, as inferências feitas sobre a variação temporal das interações microbianas neste trabalho devem ser vistas com cuidado. A despeito disto, a variação das populações estudadas não é errática e não é explicada unicamente pela variação das marés. $O$ padrão de oscilação encontrado parece refletir uma intensa atividade de predação de bactérias e picocianobactérias por nanoheterótrofos, a despeito da possibilidade de interferência de outros fatores.

\section{Agradecimentos}

Os autores agradecem à Comissão Interministerial para os Recursos do Mar (CIRM) pelo suporte financeiro; ao Consclho Nacional de Pesquisa (CNPq) pela bolsa de aperfeiçoamento científico concedida à Ana Júlia Fernandes e ao Prof. Dr Salvador Airton Gaeta pela possibilidade de utilização dos dados hidrográficos.

\section{Referências bibliográficas}

Aidar, E.; Gaeta, A. S.; Gianesella-Galvão, S. M. F.; Kutner, M. B. B. \& Teixeira, C. 1993. Ecossistema costeiro tropical: nutrientes dissolvidos, fitopâncton e clorofila- $a$ e suas relações com as condiçōes oceanográficas da região de Ubatuba, SP. Publção esp. Inst. oceanogr., São Paulo, (10):9-43.

Andersen, P. \& Fenchel, T. 1985. Bacterivory by microheterotrophic flagcllates in seawater samples. Limnol. Oceanogr., 30(1):198-202.

Andersen, P. \& Sorensen, H. M. 1986. Population dynamics and trophic coupling in pelagic microorganisms in eutrophic coastal water. Mar. Ecol.-Prog. Ser., 33:99-109.

Azam, F.; Fenchel, T.; Field, J. G.; Gray, J. S.; Meyer-Reil, L. A. \& Thingstad, F. 1983. The ecological role of water-column microbes in the sea. Mar. Ecol.-Prog. Ser., 10:257-263.

Burney, C. M.; Davis, P. G.; Johnson, K. M.; Sieburth, J. McN. 1981. Dicl flux of dissolved carbohydrate in a salt marsh and a simulated estuarine ecosystem. Mar. Biol., 63:175-187.

Burney, C. M.; Davis, P. G.; Johnson, K. M.; Sieburth, J. McN. 1982. Diel relationship of microbial trophic groups and "in situ" dissolved carbohydrate dynamics in the Caribbean sea. Mar. Biol., 65:215-219.

Campbell, L. \& Carpenter, E. J. 1986. Estimating the grazing pressure of heterotrophic nanoplankton on Synechococcus spp using the seawater dilution and selective inhibitor techniques. Mar. Ecol.-Prog. Ser., 33:121-129. 
Caron, D. A.; Lim, L. E.; Micelli, G.; Waterbury, J. B. \& Valois, F. W. 1991. Grazing and utilization of chroococcoid cyanobacteria and heterotrophic bacteria by protozoa in laboratory cultures and a coastal plankton community. Mar. Ecol.-Prog. Ser., 76:205-217.

Coffin, R. B. \& Sharp, J. H. 1987. Microbial trophodynamics in the Delaware Estuary. Mar. Ecol.-Prog. Ser., 41:253-266.

Davis, P. G.; Caron, D. A.; Johnson, P. W. \& Sieburth, J. McN. 1985. Phototrophic and pochlorotic components of picoplankton and nanoplankton in the North Atlantic; geographical, vertical, seasonal and diel distributions. Mar. Ecol.-Prog. Ser., 21:15-26.

Fenchel, T. 1982. Ecology of heterotrophic microflagellates IV. Quantitative occurrence and importance as bacterial consumers. Mar. Ecol. Prog. Ser., 9:35-42.

Fernandes, A. J. 1994. Estudo quantitativo da bacterivoria por microflagelado heterótrofo. Dissertação de mestrado. Universidade de São Paulo, Instituto Oceanográfico. 186 p.

Fuhrman, J. A. \& McManus, G. B. 1984. Do bacteria-sized marine eukariotes consume significant bacterial production? Science, 224:1257-1260.

Fuhrman, J. A.; Eppley, R. W.; Hagstrom, A. \& Azam, F. 1985. Diel variations in bacterioplankton, phytoplankton and related parameters in the Southern California Bight. Mar. Ecol.-Prog. Ser., 27:9-20.

Grashoff, K.; Ehrhardt, M. \& Kremling, R. 1983. Methods of seawater analysis. $2^{\text {nd }}$ edition. Weinheim, Verlagchemie. $419 \mathrm{p}$.

Hobbie, J. E.; Daley, R. J. \& Jasper, S. 1977. Use of Nuclepore filters for couting bacteria by fluorescence microscopy. Appl. environ. Microbiol., 33:1225-1228.

Iturriaga, R. \& Mitchell, B. G. 1986. Chroococcoid cyanobacteria: a signigicant component in the food web dynamics of the open ocean. Mar. Ecol. Prog. Ser., 28:291-297.
Johnson, P. W.; Xu, H.-S. \& Sieburth, J. McN. 1982. The utilization of chroococcoid cyanobacteria by marine protozooplankters but not by calanoid copepods. Annls. Inst. océanogr., 58(S):297-308.

Joint, I. R.; Owens, N. P. J.; Pomroy, A. J. 1986. The seasonal production of picoplankton and nanoplankton in the Celtic Sea. Mar. Ecol.-Prog. Ser., 28:251-258.

Landry, M. R.; Haas, L. W. \& Fagerness, V. L. 1984. Dynamics of microbial plankton communities: experiments in Kaneohe Bay, Hawaii. Mar. Ecol.-Prog. Ser., 16:127-133.

Larsson, U. \& Hagstrom, A. 1982. Fractionated phytoplankton primary production, exudate release and bacterial production in a Baltic eutrophication gradient. Mar. Biol., 67:57-70.

Lessard, E. J. \& Swift, E. 1985. Species-specific grazing rates of heterotrophic dinoflagellates in oceanic waters, measured with a dual label radioisotope technique. Mar. Biol., 87:289-296.

McManus, G. B. \& Fuhrman, J. A. 1988. Control of marine bacterioplankton populations: measurement and significance of grazing. Hydrobiologia, 159:51-62.

Mesquita, A. R.; Leite, J. B. A. \& Rizzo, R. 1979. Contribuição ao estudo das correntes marinhas na Plataforma entre Cabo Frio e Cananéia. Bolm Inst. oceanogr., S Paulo, 28(2):95-100.

Mesquita, A. R. \& Harari, J. 1984. Tides and tide gauges of Cananéia and Ubatuba - Brazil (Lat. $24^{\circ}$ ). Relat. int. Inst. oceanogr., Univ. S Paulo, (11):1-12.

Mesquita, H. de S. L. 1993. Densidade e distribuição do bacterioplâncton nas águas de Ubatuba $\left(23^{\circ} \mathrm{S}-45^{\circ} \mathrm{W}\right)$, Estado de São Paulo. Publção esp. Inst. oceanogr., S Paulo, (10):45-63.

Millero, F. J. \& Poisson, A. 1981. International one-atmosphere equation of state of seawater. Deep-Sea Res., 28A(6):625-629.

Nagata, T. 1988. The microflagellate-picoplankton food linkage in the water column of Lake Biwa. Limnol. Oceanogr., 33(4):504-517. 
Pomeroy, L. R. 1974. The occan's food web, a changing paradigm. Bioscience, 24:499-504.

Rassoulzadegan, R. \& Sheldon, R. W. 1986. Predator-prey interaction of nanozooplankton and bacteria in a oligotrophic marine environment. Limnol. Oceanogr., 31:1010-1021.

Ray, R. T.; Haas, L. W. \& Sieracki, M. E. 1989. Autotrophic picoplankton dynamics in a Chesapeak Bay sub-estuary. Mar. Ecol.-Prog. Ser., 52:273-285.

Shcldon, R. W.; Prakash, A. \& Sutcliff, W. H. 1972. The size distribution of particles in the ocean. Limnol. Oceanogr., 17:327-340.

Sherr, E. B.; Sherr, B. F.; Fallon, R. D. \& Newell, S. Y. 1986. Small aloricate ciliates as a major componente of the marine heterotrophic nanoplankton. Limnol. Oceanogr., 31:177-183.

Sicburth, J. McN.; Smetacek, V. \& Lenz, J. 1978. Pelagic ecosystem structure: heterotrophic compartments of the plankton and their relationship to plankton size fractions. Limnol. Occanogr., 23:1256-1263.

Sorokin, Y. 1977. The heterotrophic phase of plankton sucession in the sea of Japan. Mar. Biol., 41:107-117.

Strickland, J. D. H. \& Parsons, T. R. 1972. A pratical handbook of seawater analysis. Fish. Res. Bd. Canadá, Ottawa. 310p.
Stockner, J. G. \& Antia, N. J. 1986. Algal picoplankton from marine and freshwater ecosystems: a multidisciplinary perspective. Can.J. Fish aquat. Sci., 43:2472-2502.

Teixeira, C. \& Gaeta, A. S. 1991. Contribution of picoplankton to primary production in estuarine, coastal and equatorial waters of Brazil. Hydrobiologia, 209:117-122.

Waterbury. J. B.; Watson, S. W.; Valois, F. W. \& Franks, D. G. 1986. Biological and ccological characterization of the marine unicellular cyanobacterium Synechococcus. In: Platt, T. \& Li, W. K. W. eds Photosynthetic picoplankton. Can. Bull. Fish. aquat. Sci., 214:71-120.

Wheeler, P. A.; Kirchman, D. L.; Landry, M. R. \& Kokkinakis, S. A. 1989. Dicl periodicity in ammonium uptake and regeneration in the occan subartic Pacific: Implications for interactions in microbial food webs. Limnol. Oceanogr., 34(6):1025-1033.

Wright, R. T. \& Coffin, R. B. 1984. Factors affeting bacterioplankton density and productivity in salt marsh cstuaries. In: Klug, M. J. \& Reddy, C. A. eds Current perspectives in microbial ecology. Washington, DC, American Society for Microbiology. p. 485-494.

(Manuscrito recebido 16 novembro 1995; revisado 20 marco 1996; aceito 16 junho 1996) 